\title{
Colonoscopy in patients aged 80 years or older and its contribution to the evaluation of rectal bleeding
}

\author{
Leon Bat ${ }^{1}$, Amos Pines ${ }^{1,3}$, Eliahou Shemesh ${ }^{1}$, Yoram Levo ${ }^{3}$, Doron Zeeli ${ }^{4}$, \\ Eitan Scapa ${ }^{2}$ and Yosef Rosenblum ${ }^{1}$
}

Gastroenterology Institutes, ${ }^{1}$ Sheba Medical Center, Tel-Hashomer, and ${ }^{2}$ Assaf-Harofe Hospital, Zerifin, ${ }^{3}$ Department of Medicine 'T', Ichilov Hospital Tel-Aviv Medical Center, Tel-Aviv (affiliated to Tel-Aviv University Sackler Faculty of Medicine), and ${ }^{4}$ Geriatrics Service, The General Sick Fund, Tel-Aviv, Israel

\begin{abstract}
Summary: Colonoscopies performed in patients aged 80 years or older at the Sheba Medical Center were analysed according to the primary indication for the procedure: 101 colonoscopies were performed because of rectal bleeding of at least 2 months duration, and 335 for all other indications. Carcinoma of the large bowel was found in $29(28.7 \%)$ bleeders, with the rectum being the most frequently involved site (12 patients). Among the non-bleeders, the prevalence of cancer was significantly lower (33 cases, $9.8 \%$; $P<0.001$ ), and rectal carcinoma was less common (five patients, $P=0.04$ ), but proximal tumours were more frequent. Of patients with cancer who had operations, the majority $(72 \%)$ had a tumour confined to the bowel wall (Dukes A or B). The rate of adenomas was similar for both groups (34\% vs $29 \%$ ). The non-bleeders complained more frequently of abdominal pain or a change in bowel habits as compared to the bleeders, but both groups had similar rates for anaemia and weight loss.

In all, $47 \%$ of these octogenarians with cancer, and $26 \%$ with adenomas were referred for colonoscopy because of rectal bleeding. This procedure was found to be safe in old age, as we recorded only four ( $0.9 \%)$ non-fatal complications among our series, a similar figure to the overall incidence of complications at our Institute. In conclusion, our data indicate that rectal bleeding in octogenarians warrants a complete colonic investigation, preferably by total colonscopy.
\end{abstract}

\section{Introduction}

Rectal bleeding is an important and common manifestation of colorectal neoplasia. ${ }^{1-3}$ The presence of a tumour in patients with rectal bleeding cannot be predicted by clinical data, ${ }^{4,5}$ and therefore should be established by a radiological or colonoscopic investigation. ${ }^{6}$ Despite some debate concerning the preferred method of large bowel investigation, ${ }^{1,6-12}$ most studies favour colonoscopy over barium enema because it may be used also for biopsy and treatment of the neoplastic lesions.

It has been suggested that complications of colonoscopy are age-related and that the risk versus benefit of colonoscopy in the very old favour the use of alternative investigative modalities. ${ }^{13,14}$ This traditional approach has been recently challenged. ${ }^{15}$ The aim of our study was to evaluate the

Correspondence: Amos Pines, M.D., Department of Medicine 'T', Ichilov Medical Center, 6 Weizman Street, Tel-Aviv 64239, Israel.

Accepted: 29 November 1991 role of colonoscopy in octogenerians in general, and in those referred for investigation of recurrent rectal bleeding in particular.

\section{Patients and methods}

The majority of the inhabitants in the catchment area of the Sheba Medical Center are medically insured by the General Workers Sick Fund, which operates primary care clinics. We urged primary physicians to refer every patient with recurrent rectal bleeding for examination at our Institute, regardless of the results of any work-up which might have already been performed. Recurrent rectal bleeding was defined as multiple episodes of small amounts of bright or dark red blood per rectum, related to bowel movement.

The study population (bleeders) consisted of patients aged 80 years or more with rectal bleeding of more than 2 months duration. Those with massive bleeding, melaena or simply positive tests for occult blood were excluded from the study. 
Based on our previous experience with prolonged rectal bleeding ${ }^{16}$ all patients underwent colonoscopy. The results were compared to those obtained in octogenarians referred by primary care physicians for colonoscopy because of all other indications (non-bleeders). Preparation for colonoscopy usually consisted of one day of clear liquid diet, X-Prep ${ }^{\mathrm{Tm}}$ (Sennosoides A and B, $75 \mathrm{ml}$ taken by mouth, Rafa Industries), and tap water enemas prior to the examination. Diazepam (3-10 mg, intravenously) was used for premedication. During the procedure the patients were monitored for heart rate, blood pressure, respiration rate and electrocardiogram, and oxygen was supplemented when needed. Patients' files were searched for demographic data, details of colonoscopy (extent, reasons for inability to reach the caecum when total colonoscopy was planned, final diagnoses and complications), and post-operative grading of cancers according to the Dukes classification. Haemorrhoids or other benign anal lesions, which could be a potential source of rectal bleeding, were noted but not considered within the scope of this study, which was aimed primarily at examining the association of prolonged rectal bleeding with colorectal neoplasia.

\section{Results}

Both groups included 436 patients aged $80-101$ years. The demographic and clinical data are given in Table I. The groups were similar, but there were significantly more patients in the non-bleeding group complaining of abdominal pain or of a change in bowel habits. Only $38 \%$ of all octogenarians had had barium enema prior to colonoscopy. A tentative diagnosis of neoplasia was suggested by barium enema in $31 \%$ of colon radiographic studies in bleeders and in $20 \%$ of the non-bleeders. Success rates of the initial intended total colonoscopies in both groups and the reasons for inability to complete colonoscopy are shown in Table II. In such cases a second colonoscopy was performed, with an overall success rate of $87-89 \%$. Internal haemorrhoids (Stage II-IV) were noted in $60 \%$ of the bleeders versus $29 \%$ of non-bleeders $(P<0.001)$.

The incidence of cancer was significantly higher among the bleeders compared to the non-bleeders ( $29 \%$ vs $9.8 \% ; P<0.001)$ (Table II). However, the incidence of adenomas was similar $(28.7 \%$ vs $34 \%$; $P=0.4)$. The left colon was the most commonly involved site of cancer in the non-bleeders, but the incidence of rectal carcinomas among the bleeders was significantly higher than in the non-bleeders $(P=0.04)$. Proximal carcinomas (transverse and right colon) were more frequent in the nonbleeders. Surgery, which was performed on 45
Table I Demographic and clinical data

\begin{tabular}{|c|c|c|c|c|c|}
\hline & \multicolumn{2}{|c|}{ Bleeders } & \multicolumn{2}{|c|}{ Non-bleeders } & \multirow[t]{2}{*}{$\begin{array}{c}P \\
\text { value }\end{array}$} \\
\hline & $n$ & $\%$ & $n$ & $\%$ & \\
\hline No. of patients & \multicolumn{2}{|l|}{101} & \multicolumn{2}{|l|}{335} & \\
\hline \multicolumn{6}{|l|}{ Sex } \\
\hline Male & 53 & 52.5 & \multirow{2}{*}{\multicolumn{2}{|c|}{$\begin{array}{l}19257.3 \\
14342.6\end{array}$}} & N.S. \\
\hline Female & 48 & 47.5 & & & N.S. \\
\hline \multicolumn{6}{|l|}{ Age } \\
\hline $80-84$ & 79 & 78.1 & 255 & 76.1 & N.S. \\
\hline $85-89$ & 15 & 14.9 & 62 & 18.5 & N.S. \\
\hline $90-94$ & 5 & 5.0 & 13 & 3.9 & N.S. \\
\hline$>95$ & 2 & 2.0 & 5 & 1.5 & N.S. \\
\hline \multicolumn{6}{|l|}{ Indications } \\
\hline Rectal bleed & \multicolumn{2}{|c|}{101100.0} & 0 & 0 & - \\
\hline Abdominal pain & 4 & 4.0 & 46 & 13.7 & 0.01 \\
\hline Anaemia & 10 & 9.9 & 37 & 11.0 & N.S. \\
\hline Weight loss & 4 & 4.0 & 23 & 6.8 & N.S. \\
\hline Abdominal mass & 1 & 1.0 & 15 & 4.4 & N.S. \\
\hline $\begin{array}{l}\text { Change in bowel } \\
\text { habits }\end{array}$ & 12 & 11.9 & 112 & 30.3 & $<0.001$ \\
\hline Others & 0 & 0.0 & 9 & 2.7 & N.S. \\
\hline No symptoms ${ }^{\dagger}$ & 0 & 0.0 & 112 & 33.4 & - \\
\hline
\end{tabular}

"Cases could have more than one indication for colonoscopy; ${ }^{\dagger}$ Referred for follow-up, evaluation for pathology found in barium enema, etc.

Table II Colonoscopy success rates and results

\begin{tabular}{cccc}
\hline Bleeders & \multicolumn{3}{c}{ Non-bleeders } \\
$n$ & $\%$ & $n$ & $\%$ \\
\hline
\end{tabular}

Colonoscopy completed to

caecum

$\begin{array}{lllll}\text { Overall success rate } & 64 / 72 & 89 & 200 / 230 & 87\end{array}$

$\begin{array}{lllll}\text { At first attempt } & 48 / 72 & 66 & 143 / 230 & 63\end{array}$

Failure at first attempt due

to

Poor preparation

Technical difficulties*

Pain

Inadequate patient cooperation

Final diagnosis

Carcinoma

Adenoma $^{\dagger}$

Cancer location

Rectum

Left colon

Transverse

Right colon

Tumour stage

Dukes A

Dukes B

Dukes C

Unknown

$48 / 72 \quad 66 \quad 143 / 230 \quad 63$
Looping or fixed sigmoid, acute angulation, etc.; ${ }^{\dagger}$ Including cases with both adenoma and carcinoma; ${ }^{\ddagger} P$ (bleeders vs non-bleeders) $<0.001 ;{ }^{\S} P=0.04$. 
(73\%) cancer patients, detected early cancers (Dukes A or B) in $72 \%$ (Table II). In all, 29 of 62 ( $47 \%$ ) octogenarians (both groups) found to have cancer, and 34 of $130(26.2 \%)$ with adenomas, were referred for colonoscopy because of rectal bleeding. The rate of other endoscopic diagnoses was similar for both groups, but the non-bleeders had more normal colonoscopies than the bleeders $(22 \%$ vs $34 \% ; P=0.05$ ).

Complications were recorded in four $(0.9 \%)$ of all examinations: one vasovagal reaction following the resection of a large malignant polyp and two episodes of post-biopsy bleeding which stopped spontaneously; one perforation in the sigmoid colon was managed successfully by colostomy.

\section{Discussion}

Rectal bleeding which occurs at some time in about $15 \%$ of the general population, ${ }^{4}$ does not necessarily reflect a serious underlying pathology. The significance of rectal bleeding in the very old has not been adequately addressed in the literature. In our study we showed that rectal bleeding in patients 80 years old or more was associated with a normal colonoscopy in $22 \%$ only. Octogenarians with rectal bleeding of more than 2 months duration had a three-fold chance of having colorectal cancer when compared to non-bleeders. Rectal bleeding appeared in about a half of all patients with cancer and in approximately a quarter of those with adenomas. The incidence of haemorrhoids in bleeders was significantly higher than in non-bleeders. This is expected of course, but in view of the increased incidence of cancer in bleeders, one must recall that $41 \%$ of cancers in bleeders were located in the rectum as compared to $15 \%$ of non-bleeders, and that anorectal cancer is known to be associated with a higher prevalence of haemorrhoids. ${ }^{5,17,18}$ On the other hand, nonbleeders tended to have cancers located more proximally. This supports previous studies suggesting that right-sided cancers are less frequently manifested by rectal bleeding. ${ }^{9}$ In retrospect, even though $70 \%$ of all cancers were located within the reach of a $60 \mathrm{~cm}$ flexible sigmoidoscope, in our opinion, for the sake of the remaining $30 \%$ of cancers located proximally, old people with prolonged rectal bleeding should have a complete colonic investigation. Furthermore, a substantial number of the diagnosed tumours in our series were operable and confined to the bowel wall (Dukes A or B). This accords with the assumption that rectal bleeding is a symptom of early, rather than advanced colorectal tumour, ${ }^{3}$ again emphasizing the importance of early colonoscopic detection and prompt removal of the neoplasia.

One should note that a third of the intended total colonoscopies were not completed to the caecum at first attempt, whereas the overall success rate in our Institute is $88 \%$ (Y. Geva, M.D. thesis, Hadassa Medical School, Jerusalem, 1990). Thus, at first glance it appears that colonoscopy is a difficult procedure to be performed successfully in the aged. However, a more detailed analysis of our data shows that most failures were due to poor preparation. Preparation has been recently improved since we substituted sennosoides/enema preparation (XPrep) with polyethylene glycol balanced electrolyte solution (Golyetly).

Between 1973 and 1978, Shinya et al. ${ }^{1}$ performed 2,200 colonoscopies in patients with rectal bleeding. The oldest patient in their series was only 75 (!) years old. During the past several years there have been major technical improvements in instruments used for colonoscopy, and therefore age per se is no longer considered a limiting factor..$^{15}$ In fact, we have performed several colonoscopies in centenarians. In our overall experience of some 9,000 colonoscopies (unpublished data), we encountered $1.1 \%$ minor complications (mostly vasovagal reactions) and $0.05 \%$ major complications. These figures are similar to those observed in the present study. Hence octogenarians do not seem to have a greater complication rate of colonoscopy, especially if monitored properly while sedated. ${ }^{19}$

In conclusion, we believe that colonoscopy should be offered to all patients, whenever indicated, and regardless of their age. This procedure is of utmost importance especially in all cases presenting with prolonged rectal bleeding, in view of the high incidence of associated malignancies, mostly still confined to the bowel wall. Similar opinion was expressed recently by Forde ${ }^{12 a}$ while discussing the approach toward middle-aged persons with episodic rectal bleeding and internal haemorrhoids. The low incidence of complications observed in our study gives a further approval for the use of colonoscopy even in very old patients.

\section{Acknowledgement}

We thank Professor Paul Rozen for his help in preparing this manuscript.

\section{References}

1. Shinya, H., Cwern, M. \& Wolf, G. Colonoscopic diagnosis and management of rectal bleeding. Surg Clin North Am 1982, 62: 897-903.
2. Staniland, J.R., Ditchburn, J. \& de Dombal, F.T. Clinical presentation of diseases of the large bowel: a detailed study of 642 patients. Gastroenterol 1976, 70: 22-28. 
3. Raftery, T.L. \& Samson, N. Carcinoma of the colon: a clinical correlation between presenting symptoms and survival. Am Surg 1980, 46: 600-606.

4. Chapuis, P.H., Goulston, K.J., Dent, O.F. \& Tait, A.D. Predictive value of rectal bleeding in screening for rectal and sigmoid polyps. $\mathrm{Br}$ Med J 1985, 290: 1546-1548.

5. Goulston, K.J., Cook, I. \& Dent, O.F. How important is rectal bleeding in the diagnosis of bowel cancer and polyps? Lancet 1986, ii: $261-264$.

6. Editorial. Investigation of rectal bleeding. Lancet 1989, i: 195-197.

7. Swarbrick, E.T., Hunt, R.H., Thomas, B.M. \& Williams, C.B. Colonoscopy for unexplained rectal bleeding. $\mathrm{Br} \mathrm{Med} \mathrm{J}$ 1978, 2: $1685-1687$.

8. Irvine, E.J., O'Connor, J., Frost, R.A. et al. Prospective comparison of double contrast barium enema plus flexible sigmoidoscopy $\mathrm{v}$. colonoscopy in rectal bleeding: barium enema $v$. colonoscopy in rectal bleeding. Gut 1988, 29: 1188-1193.

9. Bowers, F.J., Hardy, T.G. Jr, Aguilar, P.S., Hartmann, R.F. \& Stewart, W.R.C. The efficacy of barium-enema examinations in patients with anorectal disease. Dis Colon Rectum 1987, 30: 285-287.

10. Guillem, J.G., Forde, K.A., Treat, M.R., Neugut, A.I. \& Bodian, C.A. The impact of colonoscopy on the early detection of colonic neoplasms in patients with rectal bleeding. Ann Surg 1987, 206: 606-611.

11. Glick, S.N., Teplick, S.K., Balfe, D.M. et al. Large colonic neoplasms missed by endoscopy. Am J Radiol 1989, 152: 513-517. 12a. Forde, K.A. Is there a need to perform full colonoscopy in a middle-age person with episodic bright red blood per rectum and internal hemorrhoids? Am J Gastroenterol 1989, 84: 1227-1228.

12b. Waye, J.D. Is there a need to perform full colonoscopy in a middle-age person with episodic bright red blood per rectum and internal hemorrhoids? Am J Gastroenterol 1989, 84: $1227-1228$.

13. Ghazi, A. \& Grossman, M. Complications of colonoscopy and polypectomy. Surg Clin North Am 1982, 62: 889-986.

14. Macrea, F.A., Tan, K.G. \& Williams, C.B. Toward safer colonoscopy: a report on the complications of 5000 diagnostic or therapeutic colonoscopies. Gut 1983, 24: 376-383.

15. DiPrima, R.E., Barkin, J.S., Blinder, M., Goldberg, R.I. \& Phillips, R.S. Age as a risk factor in colonoscopy: fact versus fiction. Am J Gastroenterol 1988, 83: 123-125.

16. Bat, L., Pines, A., Rabau, M., Niv, Y. \& Shemesh, E. Colonoscopic findings in patients with hemorrhoids, rectal bleeding and normal rectoscopy. Israel J Med Sci 1985, 21: 139-141.

17. Gooszen, H.G. The relationship between carcinoma of the rectum and hemorrhoids. Arch Chir Neerl 1978, 30: 223-229.

18. Holly, E.A., Whittemore, A.S., Aston, D.A., Ahn, D.K., Nickoloff, B.J. \& Kristiansen, J.J. Anal cancer incidence: genital warts, anal fissure or fistula, hemorrhoids and smoking. J Natl Cancer Inst 1990, 81: 1726-1731.

19. AGSE publication no. 1022: Monitoring the patients undergoing gastrointestinal endoscopic procedures. Gastrointest Endoscop 1991, 37: 120-121. 